\title{
THE RELATIONSHIP BETWEEN SERVICE FAILURE, SERVICE RECOVERY AND AIRLINE PASSENGER SATISFACTION
}

\author{
Siti Falindah Padlee', Nurul Athira Izzati Zamri², Wan Norhayati Mohamed ${ }^{3}$, Fathilah Ismail ${ }^{4}$, \\ Siti Nur 'Atikah Zulkiffli ${ }^{5}$, Noor Zatul Iffah Hussin ${ }^{6} \&$ Zaleha Mohamad ${ }^{7}$ \\ 1,2,3,4,5,6,7Faculty of Business, Economics \& Social Development, Universiti Malaysia Terengganu \\ (siti.falindah@umt.edu.my, wannor@umt.edu.my, fathilah@umt.edu.my, atikahzulkiffli@umt.edu.my, \\ zatul.iffah@umt.edu.my, zaleha.m@umt.edu.my)
}

\begin{abstract}
Service failures and the following service recovery of a firm can greatly influence customer satisfaction, customer loyalty and the relationship quality with the firm, regardless of other firm's efforts to establish strong relationships with its customers in the long run. Airlines in particular are struggling with several obstacles concerning their business continuity and ability to survive. One of the obstacles is the fact that they are subject to inevitable service failures which are unavoidable. Meanwhile, the concept of potent service recovery has become extremely vital in terms of retaining customer satisfaction. This research paper examines the relationship of service failures and service recovery and passenger satisfaction. The data was collected from domestic passengers at the Sultan Mahmud Airport in Terengganu. The relationships among the variables of the study were supported. Based on the findings of this study, it is suggested that the airline management team and staff plan an effective recovery mechanisms to rectify service failures.
\end{abstract}

KEYWORDS: Service failure, Service Recovery, Customer Satisfaction, Airline Passengers

\section{PURPOSE AND BACKGROUND}

Enhancing customer satisfaction has become a major concern of service providers and marketers. Numerous studies have emphasized the significance of satisfaction in the service industry (Curry \& Gao, 2012). Service quality is also acknowledged as being able to influence customer satisfaction and loyalty.

Due to the rapid growth of competition and the growing expectations of customers in the business environment, it is tough for many companies especially airlines to retain customers. It is impossible for every company to avoid mistakes and to cater to every customer's expectation, especially now that customers are less devoted to a brand name and more demanding no matter how good the service delivery.

Demonstrating dissatisfaction, quitting the service, supporting the same brand or spreading negative reviews are some of the consequences to a business following a failure of service. In the airline industry, which is continuously expanding service disappointment is hard to avoid. For that reason, efforts must be made to provide excellent service recovery to claw back a positive review from customers following the service failure (Curry \& Gao, 2012).

Moreover, being unable to recognise the exact needs and wants of customers has also become one of the obstacles to the delivery of excellent service (Izogo \& Ogba, 2015). Quality of service and customer satisfaction elements are often compromised (Boetsch, Bieger, \& Wittmer, 2011). A great number of research papers on service failure have been published in connection with a diverse range of industries. However, a considerable number of those studies focus on effects of service failure and recovery in the airlines and the impact of service failure on customer satisfaction also gain attention from researchers. 
According to Curry and Gao (2012), customers who are satisfied with the recovery efforts have a more favourable evaluation than those who do not face any service failures. Having an effective process to recover from a failure is vital in airline operations. Therefore, it is crucial for managers to understand reaction of customers towards failures and recovery (Curry \& Gao, 2012). Delivering excellent service quality is beneficial for determining and boosting organisation's performance in the age of competitive business environment (Namukasa, 2013). Regarding the service quality subjective nature, abundant studies have examined the issues of dimensions and measurement (Shabbir, Malik, \& Malik, 2016).

Despite the fact that service quality has gained extensive number of studies, yet service failure and recovery of airline industry in Malaysia is still relatively unexplored and requires further investigation. The unique nature of the airline service industry which is substantially different from other service industries, warrants further studies to explore the service failure and recovery of airlines and its impact on customer satisfaction and loyalty (Steven, Dong, \& Dresner, 2012).

Therefore, this study aims to assess the satisfaction levels of airlines passengers, and the impact of the service failure, subsequent recovery and resulting passenger satisfaction. In reality, service failures can often be rectified by adequate service recovery efforts. Service failure does not greatly influence customer satisfaction, instead the major influence is the service recovery effort (Bankova et al., 2018). Furthermore, service providers cannot always avoid failure because of the nature of service industry. It is more essential however that service providers respond immediately and appropriately to rectify the failure whenever failures occur.

\section{METHODOLOGY}

For this study, the researcher used a non-probability sampling technique to obtain a sample from the population. The convenience sampling technique was chosen as the technique is the most easily accessible members (Sekaran \& Bougie, 2016).

There were 300 questionnaires distributed and the total of 250 questionnaires were collected. The questionnaires were distributed to the passengers at the waiting lounge by approaching and asking them whether they would want to participate in the study. Before distributing the questionnaires, a letter of permission was sent to the airport department for approval to collect data in waiting lounge.

To achieve the objective of the study, multiple regression was applied to analyse the relationship among the variables studied.

\section{FINDINGS}

Table 1: The results of multiple regression

\begin{tabular}{lccc}
\hline & $\boldsymbol{\beta}$ & $\mathbf{T}$ & Sig. \\
\hline Constant & & & \\
Service Failure & .332 & 6.163 & .000 \\
Service Recovery & .533 & 9.229 & .000 \\
Customer Satisfaction & .583 & 9.680 & .000 \\
$\boldsymbol{R}^{2}$ & .628 & & \\
Adjusted $\boldsymbol{R}^{2}$ & .622 & & \\
\hline
\end{tabular}




\section{CONCLUSION}

Based on the findings, it shows that the relationship between service failures, service recoveries and customer satisfaction are a positive. This means that service failures influence the satisfaction levels of airline passengers. When service failures happen, customers are expecting greater efforts or skill by service provider to deal with, rectify and avoid future failures. The greater the recovery efforts shown by the service provider the more it will influence passenger satisfaction or dissatisfaction in the wake of the service failure. This also indicates that an effective recovery mechanism is extremely essential for airlines to have so that they can deal with service failures when they happen.

\section{REFERENCES}

Curry, N., \& Gao, Y. (2012). Low-cost airlines-A new customer relationship? An analysis of service quality, service satisfaction, and customer loyalty in a low-cost setting. Services Marketing Quarterly, 33(2), 104-118.

Izogo, E. E., Ogba, I.-E. (2015). Service quality, customer satisfaction and loyalty in automobile repair services sector. Int. J. Qual. Reliab. Manag. 32, 250-269. https://doi. org/10.1108/IJQRM-05-2013-0075.

Steven, A. B., Dong, Y., \& Dresner, M. (2012). Linkages between customer service, customer satisfaction and performance in the airline industry: Investigation of non-linearities and moderating effects. Transportation Research Part E: Logistics and Transportation Review, 48(4), 743-754. doi: https://doi. org/10.1016/j.tre.2011.12.006 